\title{
ARTICLE Danshensu alleviates pseudo-typed SARS-CoV-2 induced mouse acute lung inflammation
}

Wei Wang ${ }^{1}$, Sha-sha $\mathrm{Li}^{1}$, Xin-feng $\mathrm{Xu}^{1}$, Chan Yang ${ }^{1}$, Xiao-ge Niu ${ }^{1}$, Shu-xian $\mathrm{Yin}^{2}$, Xiao-yan Pan ${ }^{3}$, Wei Xu ${ }^{1}$, Guo-dong Hu${ }^{2}$, Chan Wang ${ }^{1}$ and Shu-wen Liu ${ }^{1,4}$

Severe acute respiratory syndrome coronavirus 2 (SARS-CoV-2) can induce acute inflammatory response like acute lung inflammation (ALI) or acute respiratory distress syndrome, leading to severe progression and mortality. Therapeutics for treatment of SARS-CoV-2-triggered respiratory inflammation are urgent to be discovered. Our previous study shows that Salvianolic acid C potently inhibits SARS-CoV-2 infection. In this study, we investigated the antiviral effects of a Salvia miltiorrhiza compound, Danshensu, in vitro and in vivo, including the mechanism of S protein-mediated virus attachment and entry into target cells. In authentic and pseudo-typed virus assays in vitro, Danshensu displayed a potent antiviral activity against SARS-CoV-2 with EC 50 of $0.97 \mu \mathrm{M}$, and potently inhibited the entry of SARS-CoV-2 S protein-pseudo-typed virus (SARS-CoV-2 S) into ACE2-overexpressed HEK-293T cells $\left(\mathrm{IC}_{50}=0.31 \mu \mathrm{M}\right)$ and Vero-E6 cell $\left(\mathrm{IC}_{50}=4.97 \mu \mathrm{M}\right)$. Mice received SARS-CoV-2 S via trachea to induce ALI, while the VSV-G treated mice served as controls. The mice were administered Danshensu $(25,50,100 \mathrm{mg} / \mathrm{kg}$, i.v., once) or Danshensu (25, 50, $100 \mathrm{mg} \cdot \mathrm{kg}^{-1} \cdot \mathrm{d}^{-1}$, oral administration, for 7 days) before SARS-CoV-2 S infection. We showed that SARS-CoV-2 S infection induced severe inflammatory cell infiltration, severely damaged lung tissue structure, highly expressed levels of inflammatory cytokines, and activated TLR4 and hyperphosphorylation of the NF-KB p65; the high expression of angiotensinogen (AGT) and low expression of ACE2 at the mRNA level in the lung tissue were also observed. Both oral and intravenous pretreatment with Danshensu dosedependently alleviated the pathological alterations in mice infected with SARS-CoV-2 S. This study not only establishes a mouse model of pseudo-typed SARS-CoV-2 (SARS-CoV-2 S) induced ALI, but also demonstrates that Danshensu is a potential treatment for COVID-19 patients to inhibit the lung inflammatory response.

Keywords: Danshensu; SARS-CoV-2; spike protein; acute lung inflammation; inflammatory cytokines

Acta Pharmacologica Sinica (2022) 43:771-780; https://doi.org/10.1038/s41401-021-00714-4

\section{INTRODUCTION}

The World Health Organization (WHO) issued that SARS-CoV-2 began to spread on a community scale, and the outbreak was pandemic. As of May 14, 2021, 161 million confirmed COVID-19 cases worldwide have been reported, and more than 3.3 million deaths from SARS-CoV-2. SARS-CoV-2, an enveloped singlestranded RNA $\beta$-coronavirus, is highly closed to the virus severe acute respiratory syndrome CoV (SARS-CoV) and Middle East respiratory syndrome CoV (MERS-CoV) [1]. Coronaviruses are not the dangerous factors in a broad sense, as they are found in nature and rarely infect humans, and only cause common upper respiratory tract infections, except for SARS-CoV in 2002 [2-4]. The high degree of infectivity and serious complications from SARSCoV-2 [5] have come to a formidable challenge to the clinical and public health.

To date, there are still no clinically prophylactic drugs available for COVID-19 therapy. To understand the seriousness of SARS-CoV-2 to global health and optimize the treatment of infected persons for patients, we must develop new anti-SARSCoV-2 preparations to deal with various infection symptoms. In addition to respiratory system involvement, SARS-CoV-2 infection can also cause multiple organ dysfunction [4, 6, 7]. However, the respiratory system is the main target area for SARS-CoV-2 infected patients, and SARS-CoV-2 induces severe inflammation and damage in the lung environments. Previous studies showed that less than $20(\%)$ of patients were observed in complex or extremely complex symptoms, mild symptoms were observed in most cases, and the most common symptoms were pneumonia and acute respiratory distress syndrome (ARDS) [8]. In the period of the SARS-CoV-2 epidemic, the most patients suffered from respiratory disease, even developed to a severe pneumonia. The observation results reflected the course of COVID-19, indicating that the lung is the main target of SARSCoV-2 $[9,10]$.

The occurrence of ARDS in patients with COVID-19 is a threat to the life of them and is also a major factor of prognosis [11].

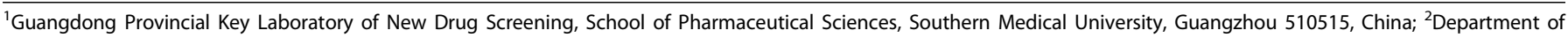
Respiratory and Critical Care Medicine, Nanfang Hospital, Southern Medical University, Guangzhou 510515, China; ${ }^{3}$ State Key Laboratory of Virology, Wuhan Institute of Virology,

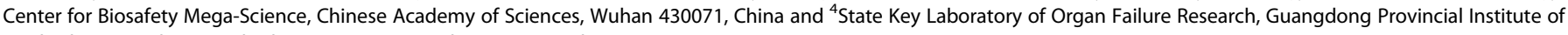
Nephrology, Southern Medical University, Guangzhou 510515, China

Correspondence: Chan Wang (wangchan0308@163.com) or Shu-wen Liu (liusw@smu.edu.cn)

These authors contributed equally: Wei Wang, Sha-sha Li, Xin-feng Xu
}

Received: 18 March 2021 Accepted: 8 June 2021

Published online: 15 July 2021 
Patients with SARS-CoV-2 associated pneumonitis or ARDS have pulmonary inflammation, thick mucus secretions in the airways, elevated levels of proinflammatory cytokines, extensive lung damage and microthrombosis [7]. Among hospitalized COVID-19 patients, 20 (\%) developed ARDS, about 65 (\%) of ARDS patients still died even though the mechanical ventilation strategies and supportive treatment had been improved [4]. Pneumonitis or ARDS is the common immune-pathological event for SARS-CoV-2 infections [11]. No effective pharmaceutical treatment for ARDS has been approved by Food and Drug Administration, and lungprotective mechanical ventilation is still an effective and indispensable treatment for this symptom [12, 13]. It is hard to be controlled in the late stage of the disease, thus early treatment is essential to ameliorate the progression of infection and improve the prognosis of SARS-CoV-2 patients.

Spike $(S)$ protein, membrane $(M)$ protein, envelope $(E)$ protein and nucleocapsid (N) protein are the structural proteins in enveloped virus SARS-CoV-2, the $S$ protein is responsible for virus attachment and invasion of target cells [14-16]. In the consideration of high risky infectivity and pathogenicity of SARS-CoV-2, experiments with SARS-CoV-2 should be performed in a Level 3 biosafety facility (BSL-3), and antiviral research is limited without BSL-3. To avoid dealing with infectious virus, we constructed a COVID-19 pseudo-virus and delivered it directly to the lungs of mice through the trachea, creating a mouse model of ALI induced by Spike protein. As to the instable situation of controlling virus with monotherapy, traditional Chinese medicines are also suggested to be considered as combination therapies with anticoronavirus chemicals for combating COVID-19 in the rapid advice guideline for the diagnosis and treatment of 2019 novel coronavirus (2019-nCoV) infected pneumonia (standard version) [17]. Danshensu (3-(3,4-dihydroxyphenyl)-lactic acid), a main water-soluble phenolic component extracted from the dried root of Chinese traditional medicine Danshen (Salvia miltiorrhiza) has been used in treating cardiovascular, cerebral, and other diseases $[18,19]$. The antioxidation, anti-apoptosis, vasodilation, inflammation regulation and lipidemia control effect of Danshensu is related with PI3K/Akt-ERK1/2/TLR4/NF-KB p65/Nrf2/HO-1, Bcl-2/ Bax, eNOS and some molecular signaling pathways $[18,20]$. Previous studies showed that Salvianolic acid B and sodium tanshinone II A sulfonate could prevent pulmonary fibrosis through anti-inflammatory and anti-fibrotic process [21]. Ovalbumin-sensitized allergic asthma could be ameliorated with the treatment of Salvia miltiorrhiza water extraction in mice [22]. Our previous results also indicated that Salvianolic acid $C$ has shown the ability of inhibiting SARS-CoV-2 infection [23]. In this study, we discovered a Salvia miltiorrhiza compound, Danshensu, which might have some beneficial effect on SARS-CoV-2 infection. Thus, we evaluated the antiviral behaviors of this Salvia miltiorrhiza compound in vitro and in vivo, including the mechanism of $S$ protein-mediated virus attachment and entry into target cells.

\section{MATERIALS AND METHODS}

\section{Chemicals}

Danshensu (purity $\geq 98$ (\%)) was purchased from Macklin Biochemical. (Shanghai, China); chloroquine (CQ) (purity $\geq 99.8$ (\%)) was purchased from TargetMol (Shanghai, China).

\section{Animals}

All animal experiments and protocols were approved by the National Institutional Animal Care and Medical Ethics Committee of Southern Medical University. And the methods applied in this study were carried out in accordance with the approved guidelines. Adult BALB/c mice (male, 6-8 weeks, $20 \pm 2 \mathrm{~g}$ ) were obtained from the Center of Experiment Animals of Southern Medical University (Guangzhou, China). Mice were housed in standard cages with adequate food and water. The temperature and humidity of room were controlled.

A total of 48 mice were used in this study and randomly separated into 6 groups $(n=8)$, including blank group ( $24 \mathrm{~h}$ and $72 \mathrm{~h}$ ), VSV-G group ( $24 \mathrm{~h}$ and $72 \mathrm{~h}$ ), SARS-CoV-2 S group ( $24 \mathrm{~h}$ and $72 \mathrm{~h}$ ). ALI model was induced by SARS-CoV-2 $S$ via trachea in SARS-CoV-2 $S$ groups, while blank groups received DMEM via trachea and VSV-G groups received VSV-G via trachea.

Another total of 72 mice were used in this study and randomly separated into 9 groups $(n=8)$, including blank group, VSV-G group, SARS-CoV-2 S group, Danshensu $25 \mathrm{mg} / \mathrm{kg}$ group, Danshensu $50 \mathrm{mg} / \mathrm{kg}$ group, Danshensu $100 \mathrm{mg} / \mathrm{kg}$ group, Danshensu $25 \mathrm{mg} / \mathrm{kg}$ i.v. group, Danshensu $50 \mathrm{mg} / \mathrm{kg}$ i.v. group, Danshensu $100 \mathrm{mg} / \mathrm{kg}$ i.v. group. Blank group received distilled water orally, VSV-G group received distilled water orally, SARS-CoV-2 S group received distilled water orally. Danshensu i.v. groups received distilled water orally, and only received Danshensu (i.v. 25, 50, or $100 \mathrm{mg} / \mathrm{kg}$, dissolved in normal saline for tail vein injection) once before the intratracheally received SARS-CoV-2 S at the 7th day; Danshensu groups received Danshensu (Oral administration. 25, 50 , or $100 \mathrm{mg} / \mathrm{kg} / \mathrm{d}$, dissolved in distilled water) orally. All groups except Danshensu (i.v. 25, 50, or $100 \mathrm{mg} / \mathrm{kg}$ ) were administrated once daily for 7 continuous days, Danshensu (i.v. 25, 50, or 100 $\mathrm{mg} / \mathrm{kg}$ ) groups just received distilled water orally for 7 continuous days before the tail vein injection. ALI model was induced by SARS-CoV-2 S via trachea after the last treatment, blank groups received DMEM via trachea and VSV-G groups received VSV-G via trachea.

Hematoxylin-eosin (H\&E) staining and immunohistochemistry The lung tissues ( $n=6$ per group) were randomly selected in each group for histologic analysis. Lung tissue samples were fixed in $4 \%$ paraformaldehyde with $24 \mathrm{~h}$ before embedded in paraffin and cut into $5 \mu \mathrm{m}$ thick sections. Sections were stained with hematoxylin and eosin (H\&E) or SARS-CoV-2 Spike (40589-V08B1, Sino Biological, Beijing, China). Finally, histopathology was observed under an optical microscope (Zeiss, Oberkochen, Germany). The lung injury score standard was followed with previous references [24]. The following four indicators were used for scoring: 1) Intrapulmonary hemorrhage; 2) The presence or absence of congestion in the pulmonary capillary; 3 ) The presence of absence of cell infiltration in lung interstitium; 4) Formation of hyaline membrane (thickened alveolar wall); the lung injury score standard was as follows: 0, normal; 1 , extremely mild damage $(<25 \%$ area of visual field); 2 , mild damage $(25 \%-50 \%$ area of visual field); 3, moderate damage (50\%-75\% area of visual field); and 4 , severe damage ( $>75 \%$ area of visual field) [24].

\begin{tabular}{|ll|}
\hline Table 1. & Sequences for real-time PCR. \\
\hline Gene & Sequence $\left(5^{\prime}-3^{\prime}\right)$ \\
\hline GAPDH & Forward AAATGGTGAAGGTCGGTGTGAAC \\
& Reverse CAACAATCTCCACTTTGCCACTG \\
TNF- $\alpha$ & Forward CCTCCCTCTCATCAGTTCTA \\
& Reverse GGCAGCCTTGTCCCTTGAC \\
IL-1 $\beta$ & Forward TTCGAGGCACAAGGCACAACA \\
& Reverse AGGTCCTGGAAGGAGCACTTCA \\
IL-6 & Forward CCACTTCACAAGTCGGAGGCTTA \\
& Reverse CCAGTTTGGTAGCATCCATCATTTC \\
ACE2 & Forward CTCTGGGAATGAGGACACGG \\
& Reverse GGTTGGGCACTGCTTACAAC \\
AGT & Forward TGTCTAGGTTGGCGCTGAAG \\
& Reverse GATGTATACGCGGTCCCAG \\
\hline
\end{tabular}


qRT-PCR

Total RNA was extracted using the Total RNA Isolation Kit (Foregene, Chengdu, China) and reverse transcribed using PrimeScript $^{\text {TM }}$ RT Master Mix (Takara, Beijing, China) according to the manufacturer's instructions. The used sequences are shown in Table 1.

\section{Pseudo-virus transduction}

Pseudo-typed SARS-CoV-2 plasmid was kindly provided by Prof Shi-bo Jiang from Fudan University. Pseudo-typed SARS-CoV-2 particles were produced in HEK293T cells as previously described [25]. In brief, cells were co-transfected with pNL4-3.luc.R-E- and pCDNA-SARS-CoV-2 plasmids at a ratio of 2:1 by PolyJet (SignaGen, Frederick, Maryland, USA). The supernatant containing the pseudo-typed SARS-CoV-2 was harvested $48 \mathrm{~h}$ later, and enriched with Amicon Ultra (Merck, Darmstadt, Germany), aliquoted and stored at $-80^{\circ} \mathrm{C}$ until use.

\section{Antiviral activity experiments in vitro}

Vero-E6 cells were infected with SARS-CoV-2 $(\mathrm{MOI}=0.05)$ at $37^{\circ} \mathrm{C}$ for $1 \mathrm{~h}$ before the pre-incubation of Danshensu and Vero-E6 cells for $1 \mathrm{~h}$. After that, fresh medium with Danshensu was added, $150 \mu \mathrm{L}$ supernatant was collected for testing after $24 \mathrm{~h}$, the copy number of the virus was determined by qRT-PCR, and the ability of Danshensu resisting SARS-CoV-2 was evaluated.

SARS-CoV-2 S was mixed with Danshensu in different concentrations in advance at $37^{\circ} \mathrm{C}$ for $30 \mathrm{~min}$, and the $100 \mu \mathrm{L}$ mixture was added to ACE2 HEK-293T and Vero-E6 cells with ACE2 overexpression. After co-incubation for $12 \mathrm{~h}$, the supernatant was discarded, and the same volume of fresh medium was replenished. After $48 \mathrm{~h}$, the cells were washed with PBS and lysed. The Luciferase level in cell lysates was detected as previously described [23] to evaluate the anti-SARS-CoV-2 S ability of Danshensu.

Indirect immunofluorescence assay

After SARS-CoV-2 inhibition assay, Vero-E6 cells on 48 well plate were fixed overnight with 4\% paraformaldehyde (Bio-Rad, Hercules, CA, USA), then infiltrated with $0.2 \%$ Triton X-100 (Sigma, Shanghai, China) for $20 \mathrm{~min}$ and incubated by immunofluorescence staining of rabbit anti-NP polyclonal overnight at $4{ }^{\circ} \mathrm{C}$. After that, goat anti-rabbit IgG H\&L was used as secondary antibody to incubate for $1 \mathrm{~h}$ at room temperature and the nuclei were stained by DAPI [23]. Axio Observer microscope (Zeiss, Oberkochen, Germany) was used to acquire fluorescence images.

\section{SARS-CoV-2 S-induced ALI}

The model of SARS-CoV-2 S-induced ALI was previously described in detail [26]. After $24 \mathrm{~h}$, blank group ( $24 \mathrm{~h})$, VSV-G group ( $24 \mathrm{~h}$ ) and SARS-CoV-2 S group ( $24 \mathrm{~h}$ ) were sacrificed under anesthesia for experimental evaluation. After a further $72 \mathrm{~h}$, rest of mice were sacrificed under anesthesia for experimental evaluation. The concentration of p24 in SARS-CoV-2 S and VSV-G was detected by ELISA and $2.5 \mathrm{mg} / \mathrm{kg}$ was settled to be the standard of SARSCoV-2 S and VSV-G dosage induced by intratracheal instillation in vivo.

Western blot analysis

Protein was extracted from cells and mouse lung tissues, SARSCoV-2 Spike and SARS-CoV-2 Spike 2 (40590-T62 and 40589V08B1, Sino Biological), TLR4 (BA1717, Boster Biological Technology, Wuhan, China), NF-KB p65 (8242 S, Cell Signaling Technology, Danvers, MA, USA), Phospho-NF-KB p65 (p-NF-kB p65) (3033, Cell Signaling Technology), and GAPDH (FD0063, Hangzhou Fude Biological Technology, Hangzhou, China), were added to membranes. Goat Anti-Rabbit HRP IgG (FDR007) and Goat Anti-Mouse HRP IgG (FDM007) were obtained from Hangzhou Fude Biological Technology.
Enzyme-linked immunosorbent assay (ELISA)

The serum of each mouse was collected, and tests were manufactured according to instructions of each ELISA kit (Shanghai Enzymelink Biotechnology, Shanghai, China).

\section{Statistical analysis}

Data were expressed as the mean \pm SD and analyzed using oneway ANOVAs. Differences were considered significant when $P<$ 0.05 . All analyses were performed using SPSS for Windows, version 22.0.0.0 (SPSS, Chicago, IL, USA) [27].

\section{RESULTS}

Effects of Danshensu on SARS-CoV-2 and S protein-pseudo-typed virus in vitro

As shown in Fig. 1a, e, Danshensu showed the potent antiviral activity with $\mathrm{EC}_{50}$ of $0.97 \mu \mathrm{M}$ and a concentration-dependent manner in inhibiting SARS-CoV-2. Danshensu was also identified to potently inhibit the entry of SARS-CoV-2 S protein-pseudotyped virus (SARS-CoV-2 S) into ACE2-overexpressed HEK$293 \mathrm{~T}$ cells $\left(\mathrm{IC} \mathrm{C}_{50}=0.31 \mu \mathrm{M}\right)$ and Vero-E6 cell $\left(\mathrm{I} \mathrm{C}_{50}=4.97 \mu \mathrm{M}\right)$ (Fig. 1b, c), but it had no significant inhibitory effect on VSV-G pseudo-virus (Fig. 1d). The $S$ protein could only be detected from supernatants containing SARS-CoV-2 $\mathrm{S}$ to confirm the pseudotyped SARS-CoV-2 as observed in Fig. 1f. In total, Danshensu has shown a potential antiviral ability against SARS-CoV-2.

SARS-CoV-2 S protein could induce pathological changes in the lung tissues

As shown in Fig. 2a, the mice in the blank group and VSV-G group showed normal architecture morphologically, while the mice in SARS-CoV-2 S group showed lung pathological damage including hemorrhage in the alveolar spaces, thickened alveolar walls, and inflammatory cells infiltration, and a large amount of $S$ protein (Fig. 2b). All these appearances were same as the ALI induced by SARS-CoV-2, with severe acute lung inflammation symptoms.

Danshensu could prevent SARS-CoV-2 S protein-induced acute lung inflammation

H\&E staining was conducted to observe the protective effect of Danshensu on physiological impairment. As revealed in Fig. 3, pathological changes in lung tissue of mice in each group were observed with a microscopic analysis after H\&E staining. The alveolar structure of mice in the VSV-G group was normal, without the hemorrhages, shrink of alveolar space, noticeable thickening of the alveolar septum or inflammatory cell infiltration. After establishing the model, mice in the SARSCoV-2 S group exhibited a thickened alveolar septum, collapsed and reduced alveoli, and marked inflammatory cell infiltration. In contrast, these changes were obviously alleviated by Danshensu in a dose-dependent manner. In the Danshensu 50 and $100 \mathrm{mg} / \mathrm{kg}$ groups, the alveolar septum was slightly thickened, a few inflammatory cells could be seen and some of the alveoli were shrunken in appearance (Fig. 3c, d). Lung histological scores in the SARS-CoV-2 S group were significantly higher than the blank group and VSV-G group, while lung histological scores in the Danshensu 50 and $100 \mathrm{mg} / \mathrm{kg}$ groups and Danshensu i.v. $100 \mathrm{mg} / \mathrm{kg}$ groups were significantly lower than in the SARS-CoV-2 S group (Fig. 3a, d) (all $P<0.05$ ). Analytical results demonstrated that Danshensu obviously ameliorated the histopathological condition in SARS-CoV-2 Sinduced acute lung inflammation.

Danshensu ameliorated inflammatory cytokines in serum and lung tissue

The effects of Danshensu on serum cytokines including IL- 6 , IL-1 $\beta$, and TNF-a were examined with ELISA kits. As revealed in Fig. $4 a-c$, 
a

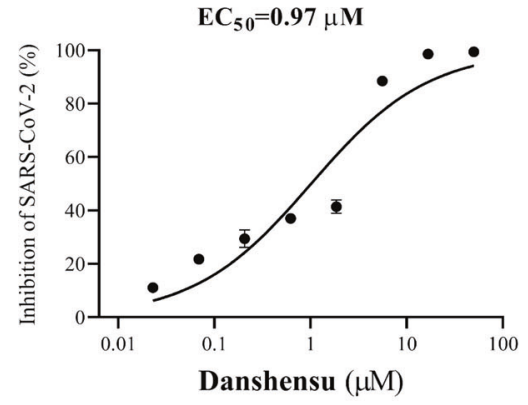

C

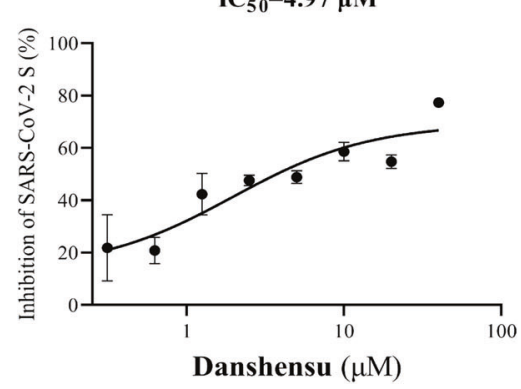

b

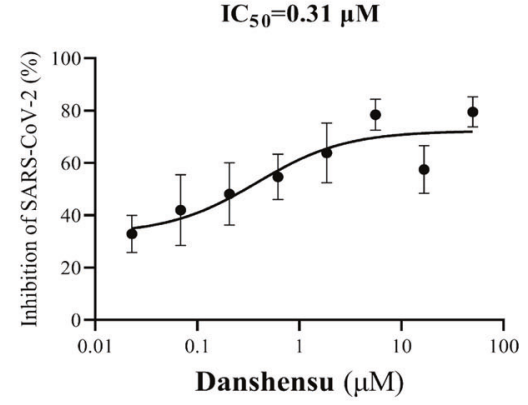

d

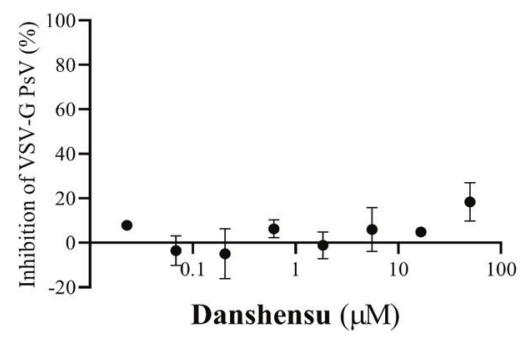

e

Danshensu $(\mu \mathrm{M})$

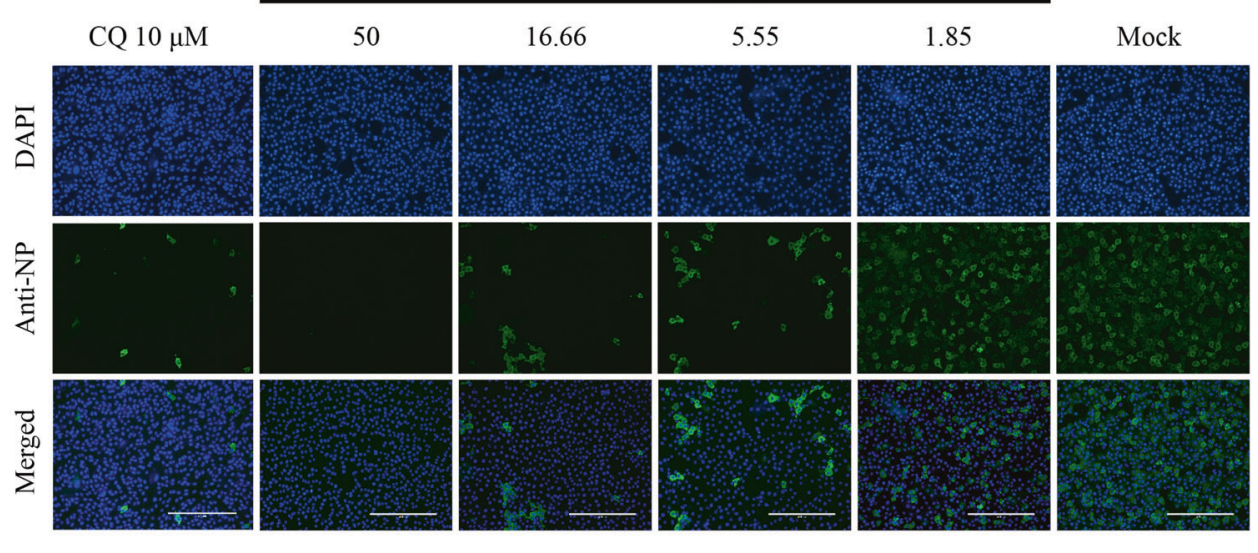

$\mathrm{f}$

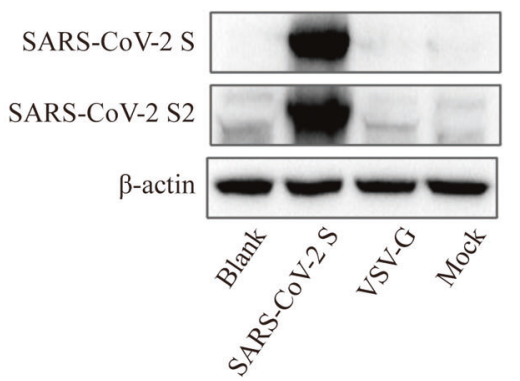

Fig. 1 The mechanism of Danshensu inhibits SARS-CoV-2 and SARS-CoV-2 S infection on 293 T/ACE2 cells. a Validation on the antiviral activity of Danshensu against SARS-CoV-2 in Vero-E6 cells. b Danshensu inhibited the entry of SARS-CoV-2 S on ACE2-overexpressed HEK293T. c Danshensu inhibited the entry of SARS-CoV-2 S on Vero-E6 cells. d The inhibitory activity of Danshensu on VSV-G. e The inhibitory activity of Danshensu on infections (green) was detected by indirect immunofluorescence assay. The nucleus (blue) was stained with DAPI, scale bar $=200 \mu \mathrm{m}$. f Pseudo-typed SARS-CoV-2 on Western blotting analysis.

the levels of TNF- $a, \mathrm{IL}-1 \beta$, and IL- 6 in serum samples presented apparent increases with SARS-CoV-2 S stimulation, compared to the blank and VSV-G groups. However, Danshensu significantly reduced the levels of TNF- $\alpha$, IL- $1 \beta$ and IL- 6 in the serum, compared with those in the SARS-CoV-2 S group.
Expression of the mRNA for TNF- $\alpha$, IL- $1 \beta$, and IL- 6 was detected in the lung of all group mice, as shown in Fig. $4 d-f$. TNF- $a, I L-1 \beta$, and IL- 6 were significantly reduced by the treatment with Danshensu 50 and $100 \mathrm{mg} / \mathrm{kg}$, whereas SARS-CoV-2 S elevated the mRNA levels of these pro-inflammatory biomarkers. 
a

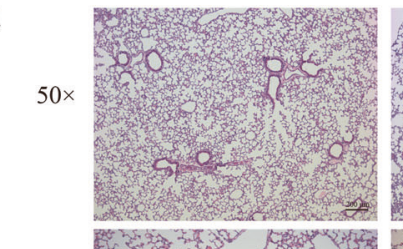

$100 \times$

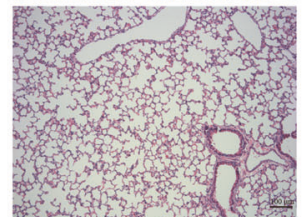

$200 \times$

DMEM

VSV-G

SARS-CoV-2 S

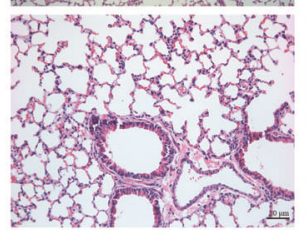

Butal
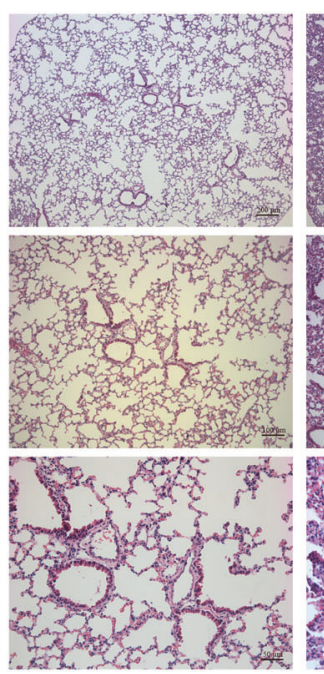

$+$
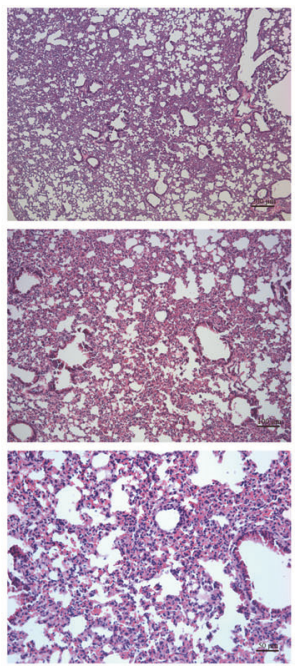

$+$

b

$200 \times$
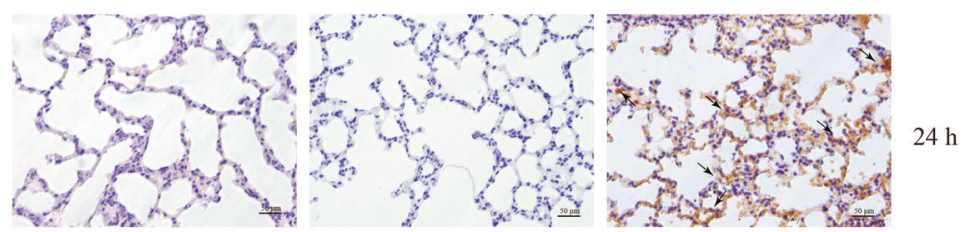

$24 \mathrm{~h}$

$200 \times$
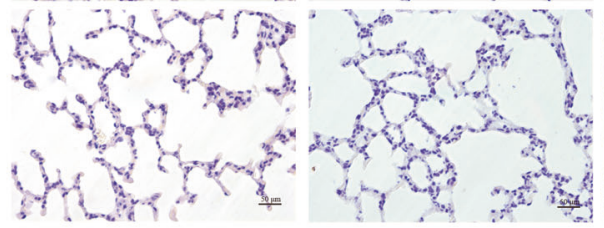

DMEM

VSV-G

SARS-CoV-2 S
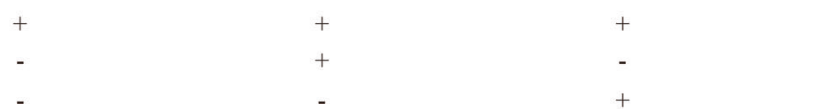

Fig. 2 SARS-CoV-2 S induced acute lung inflammation. a Pathological changes in lung tissue of mice in each group. b Immunohistochemistry of anti-SARS-CoV-2 Spike in SARS-CoV-2 S-induced mice lung tissue after $24 \mathrm{~h}$ and $72 \mathrm{~h}$.

The antioxidant system could be protected by treatment with Danshensu

Fig. 4 illustrated the effects of Danshensu on oxidative stress. SARS-CoV-2 S administration decreased CAT (Fig. 4h) and GPx (Fig. 4i) activities. In contrast, pretreatment with Danshensu enhanced the activities of CAT and GPx.

The regulation of $\mathrm{p}-\mathrm{NF}-\mathrm{KB}$ p65 and TLR4 expression in SARS-CoV-2 S-induced lung tissues by Danshensu

TLR4 is the traditional regulating receptor in the NF-KB p65 pathway and, indirectly, have operated an important role in the upregulation of TNF- $\alpha$, IL-1 $\beta$, and IL-6. As depicted in Fig. 5a, SARSCoV-2 S-treated mice showed obvious upregulation of pneumonic expressions of TLR4 and p-NF-kB p65. However, Danshensu effectively suppressed the activations of TLR4 and NF-KB p65 in the lung tissues of SARS-CoV-2 S-treated mice.

Danshensu could reverse the mRNA expression of ACE2, AGT, and inflammatory cytokines in SARS-CoV-2 S-induced lung tissues The lung of mice was analyzed by $\mathrm{qPCR}$, to assess the induction of mRNA for ACE2 and AGT. Expression of the mRNA for ACE2 and AGT was detected in the lungs of all mice, as shown in Fig. 5b, c. AGT was significantly reduced by the treatment of Danshensu (Fig. 5c), whereas SARS-CoV-2 S elevated the mRNA levels of AGT.
The mRNA level of the ACE2 was significantly promoted by the treatment with Danshensu (Fig. 5b). Danshensu i.v. at the dose of $100 \mathrm{mg} / \mathrm{kg}$ and pretreatment with Danshensu effectively reduced the mRNA expression of pro-inflammatory genes AGT to the normal levels and elevated the mRNA expression of ACE2. Danshensu i.v. at $50 \mathrm{mg} / \mathrm{kg}$ did also diminish the mRNA expression of AGT in some cases.

\section{DISCUSSION}

Danshensu is a pure molecule derived from the root of Salvia miltiorrhiza, it might be therapeutically used for antioxidation, anti-apoptosis, and anti-inflammation in various diseases [18]. Previous studies indicated that Salvianic acid A and Salvianic acid $C$ has anti-inflammatory, antioxidant and anti-acute myocardial ischemia effects and could protect against acute myocardial ischemia, especially the Salvianolic acid $C$ has shown the ability of inhibiting SARS-CoV-2 infection by blocking the formation of sixhelix bundle core of spike protein [23, 28-30]. Our results showed that Danshensu also has the antiviral properties with $\mathrm{EC}_{50}$ of 0.97 $\mu \mathrm{M}$ in SARS-CoV-2 infection, and inhibited SARS-CoV-2 S infection in a dose-dependent manner as observed in Fig. 1, meaning that Danshensu could be a potential treatment of COVID-19. More reports on histopathological changes in COVID-19 patients were 


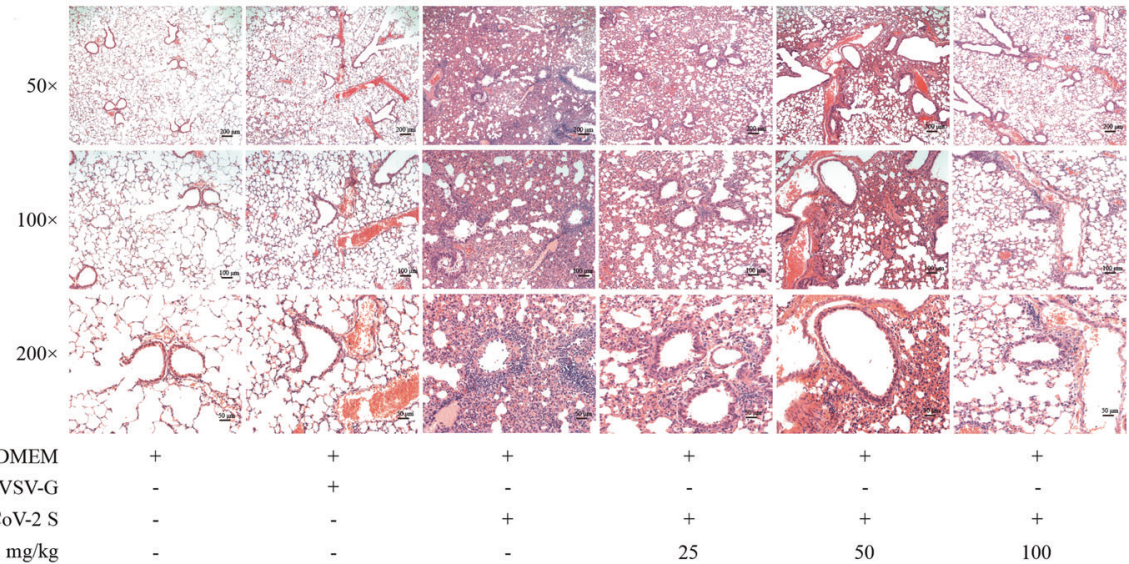

b

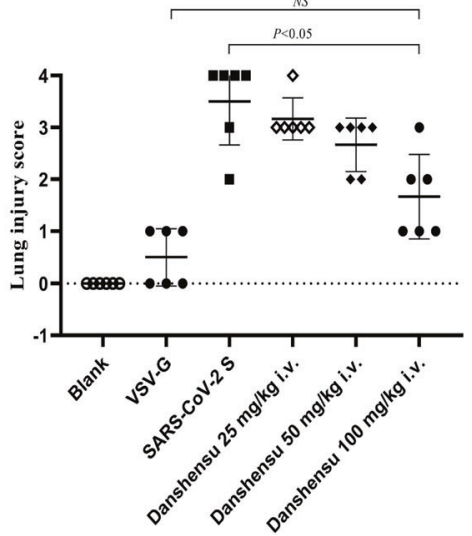

C

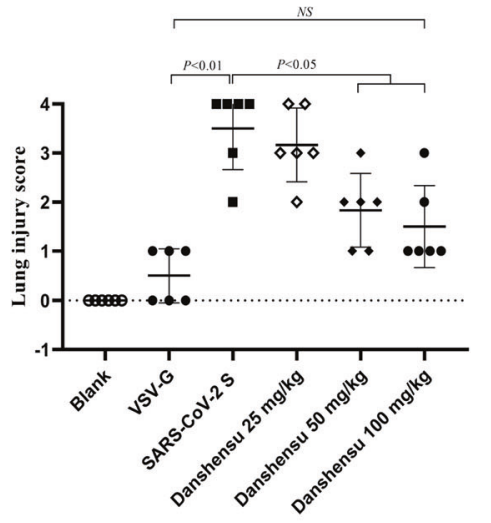

d
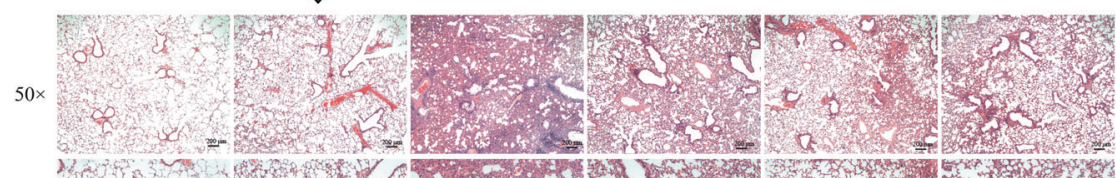

$100 \times$
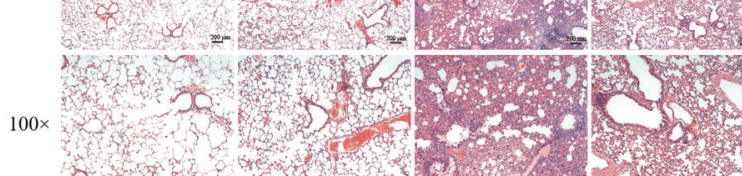

$200 \times$

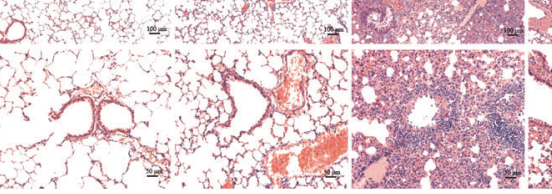

$$
\begin{aligned}
& + \\
& - \\
& -
\end{aligned}
$$

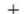

$+$

$+$

$+$

-

-

25

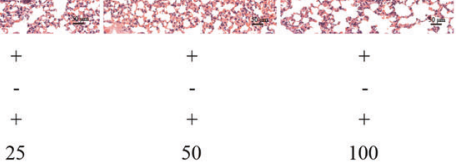

Fig. 3 SARS-CoV-2 S-induced acute lung inflammation with Danshensu treatment. a Pathological changes in lung tissue of mice in each group. $\mathbf{b}$ Lung inflammation score of blank group, VSV-G group, SARS-CoV-2 S group and Danshensu i.v. groups. $\mathbf{c}$ Lung inflammation score of blank group, VSV-G group, SARS-CoV-2 S group and Danshensu groups. d Representative microscopic pictures of H\&E staining in each group.

providing and approving established effect of ACE2 expression and activity in disease pathogenesis [31]. In the emergency of the SARS-CoV-2 pandemic, chance of infection is equal for the tissues and organs at which ACE2 is widely distributed, even a lot of SARS-CoV-2 targeting determinants have been well recognized. Respiratory system has always been the most influenced to the pathophysiological changes in human body by the infection of SARS-CoV-2, implying that some other mechanisms are involved in respiratory system disease caused by SARS-CoV-2 infection.

The model of SARS-CoV-2 in mice was built by humanized ACE2 mice, we tried to find a SARS-CoV-2 model in BALB/c mice without humanized ACE-2 in vivo. Pseudo-virus is always used to be a common type in most anti-virus experiments. At present, it has been reported that SARS-CoV-2 S was used to establish and validate a pseudo-virus neutralization assay for SARS-CoV-2 [32]. Therefore, we developed a pseudo-virus model by SARS-CoV-2 S to study the virus entry and test Danshensu on this assay in vivo. ALI was successfully established after mice were injected in tracheal administration route with SARS-CoV-2 S for $72 \mathrm{~h}$, evidenced by a significant increase in inflammatory cytokines serum levels and accompanying histopathological changes.

Inflammatory cellular infiltration in alveolar walls and thickening of alveolar walls were obviously observed in SARS-CoV-2 $\mathrm{S}$-challenged mice. The ALI was scored with the scoring system by Szarka et al. [33]. Pathology evaluation in SARS-CoV-2 Sinduced mouse acute lung inflammation model was higher than 
a

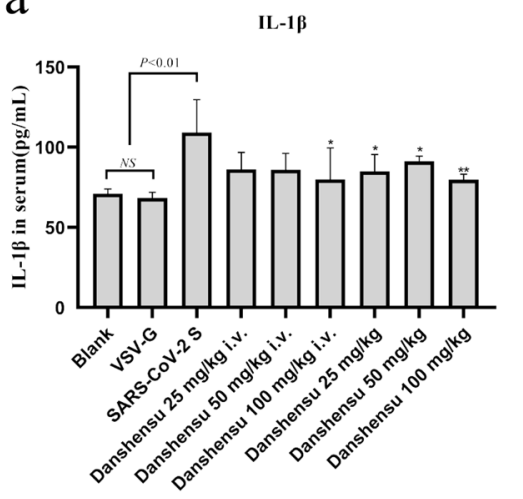

b

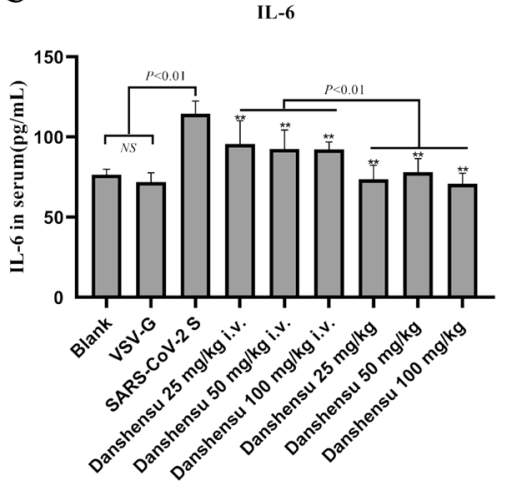

$\mathrm{C}$

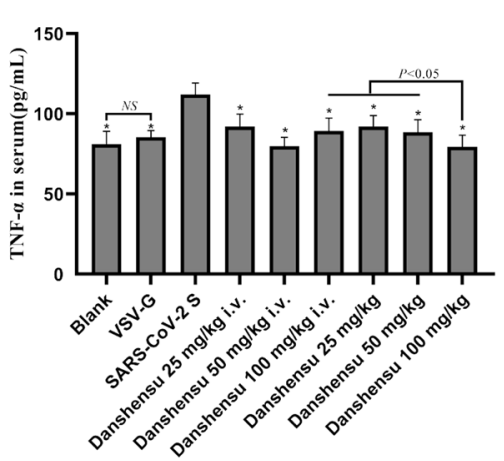

d

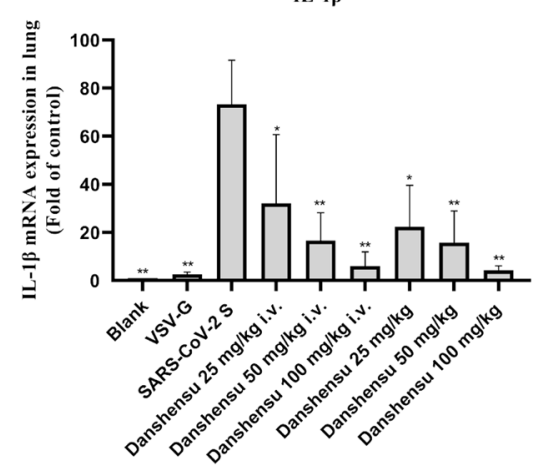

e

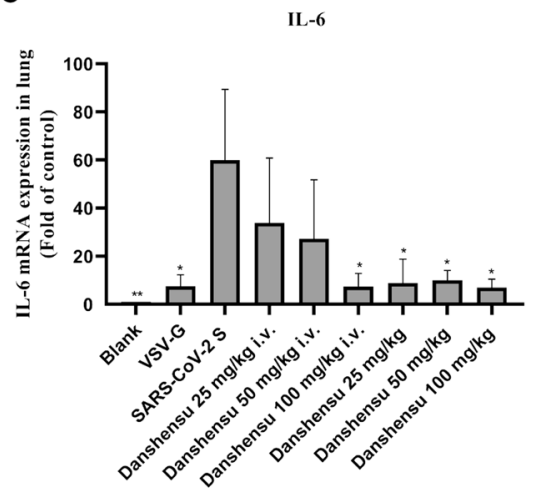

f

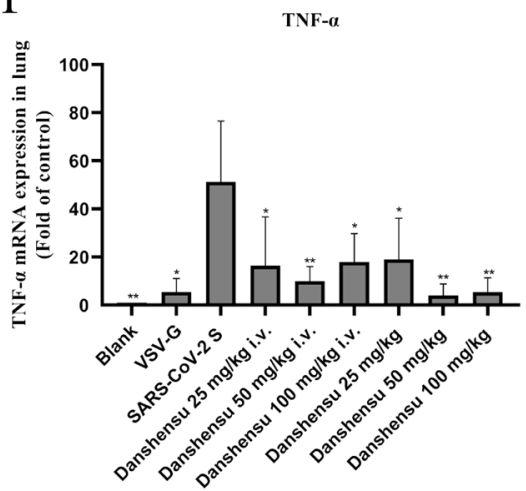

$\mathrm{g}$

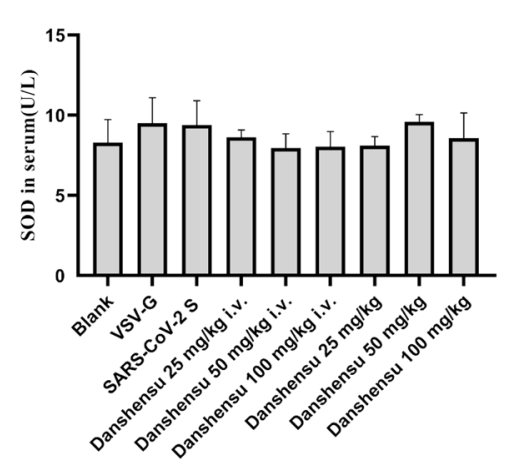

h

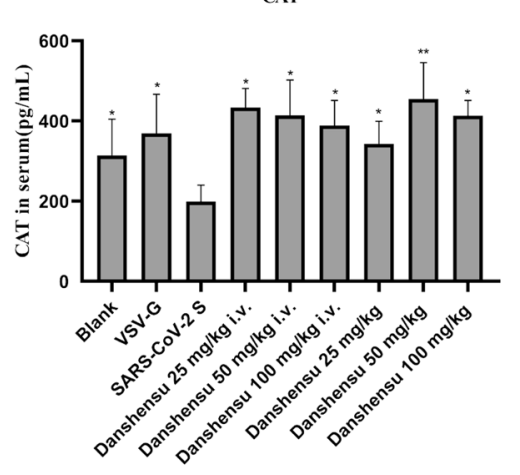

i

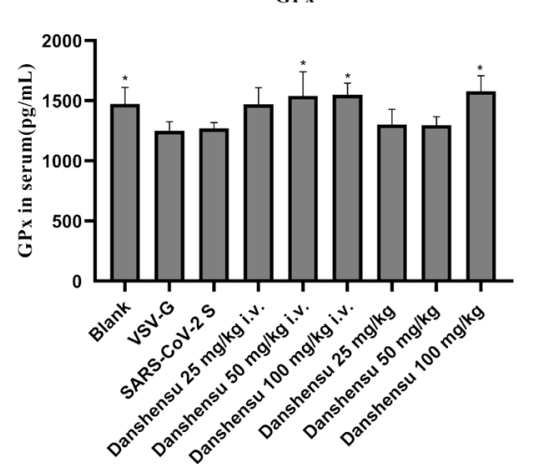

Fig. 4 Effects of Danshensu on inflammatory cytokines in serum and lung tissue. a The levels of IL-1 $\beta$ in serum in different groups. b The levels of IL- 6 in serum in different groups. c The levels of TNF- $\alpha$ in serum in different groups. $\mathbf{d}$ The expression of the mRNA for IL-1 $\beta$ in lung tissues. e The expression of the mRNA for IL- 6 in lung tissues. $\mathbf{f}$ The expression of the MRNA for TNF- $\alpha$ in lung tissues. $\mathbf{g}$ The levels of SOD in serum in different groups. $\mathbf{h}$ The levels of CAT in serum in different groups. $\mathbf{i}$ The levels of GPx in serum in different groups. Compared to SARSCoV-2 S group, ${ }^{*} P<0.05,{ }^{* *} P<0.01$.

that of blank and VSV-G group (Fig. 2a). We found that Danshensu pretreatment could ameliorate inflammatory cytokines levels and improve histopathological changes in SARS-CoV-2 S-induced ALI. Results of our experiments demonstrated that SARS-CoV-2 S caused significant increases in the levels of inflammatory cytokines, whereas Danshensu reduced the inflammatory changes and the histopathological changes in SARS-CoV-2 S-induced ALI. Our results indicated that ALI and overexpressed inflammatory factor in the lung were developed by SARS-CoV-2 S in normal mice without the involvement of humanized ACE2, other receptors such as TLR4 could be the virus induced inflammation receptors. The histological analysis showed that Danshensu performed a protective effect against the inflammatory cell infiltration and thickening of alveolar space caused by SARS-CoV-2 S in mice.
Inflammatory mediators, such as IL-1 $\beta, \mathrm{IL}-6$, and TNF- $\alpha$ were involved in SARS-CoV-2 S-induced lung damage. These inflammatory factors were significantly increased after SARS-CoV-2 S treatment, and were alleviated by pretreatment with Danshensu in our experiment. According to reports, macrophages could release inflammatory cytokines with the stimulation of SARS-CoV2 , and the secretome of many inflammatory diseases are affected by the inflammatory cytokines TNF- $\alpha$, IL-1 $\beta$ and IL-6 [34]. Furthermore, previous reports also demonstrated that the downregulation of TNF-a, IL-1 and IL- 6 production could alleviate lung inflammation. The results of this research showed that the inflammatory cytokine was markedly inhibited by pretreatment with Danshensu and SARS-CoV-2 S-induced acute lung inflammation could be reversed by ameliorating inflammatory responses. 


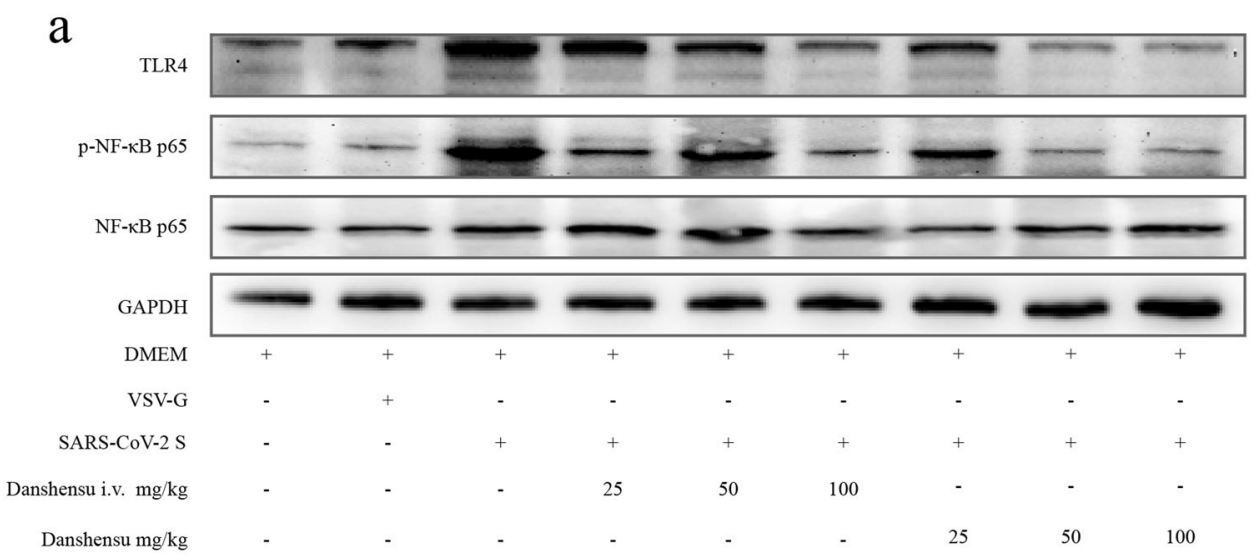

b

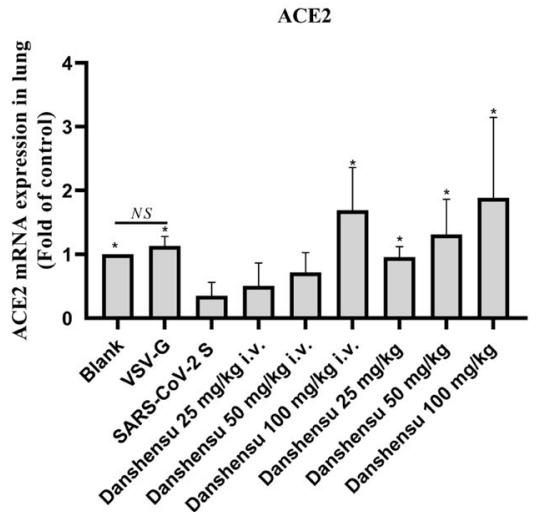

C

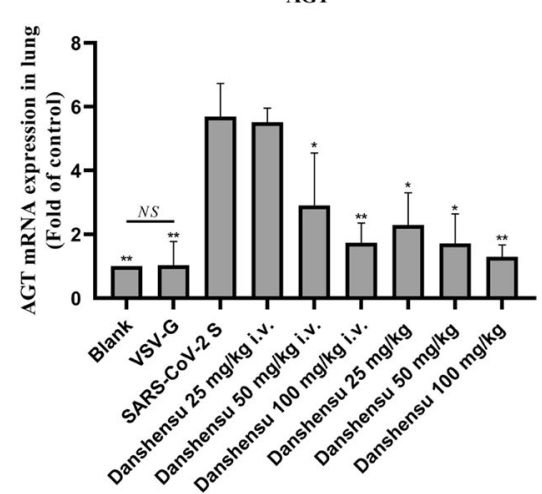

Fig. 5 Effects of Danshensu on the protein expression of p-NF-kB p65 and TLR4 in SARS-CoV-2 S-induced lung tissues and the mRNA

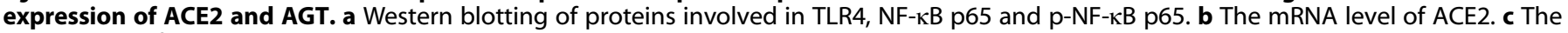
mRNA level of AGT. Compared to SARS-CoV-2 S group, ${ }^{*} P<0.05,{ }^{* *} P<0.01$.

The signal cascade that controls cytokine and stress response is closely related to TLR4 and NF-KB p65 pathway [35-37]. The innate immune receptor TLR4 could perform a role in the activation of foam cell formation and pro-inflammatory cytokines transcriptions by binding its ligands [38]. The inflammatory response mediating mechanism is related with the motivation of myeloid differentiation primary response protein 88 (MyD88)-dependent signaling and NF-KB p65 pathway by the activated TLR4, previous research showed that the NF-KB p65 signaling pathway is involved in the regulation of inflammatory mediators and plays a vital role [39]. Inflammatory cytokines can be activated from the hyperphosphorylation of the NF-KB p65 pathway and cause lung inflammation [40]. NF-KB is a nuclear transcription factor that regulates the expression of various genes, these genes are critical for inflammatory responses [41, 42]. Many inflammationassociated genes, such as TNF- $\alpha, \mathrm{IL}-1 \beta$, and IL- 6 are under the regulation of $\mathrm{p} 65$ in NF-KB family which is activated by TLR4 $[43,44]$. Reacting to oxidative stress, the onset of inflammation in the lung is triggered by activated NF-KB transcription factor [45]. The former study reported that Danshensu exerted antivasoconstriction effects with the concentration of $0.2 \mathrm{mg} / \mathrm{mL}$ in $\mathrm{CaCl}_{2}$-induced rat models of vasoconstriction [46]. Danshensu also attenuated streptozotocin-induced increases in the expressions of RAGE, p-p38, and COX-2 and the activation of NF-KB p65 pathway, ameliorated the inflammatory mediators TNF-a, IL-6, and $\mathrm{PGE}_{2}$ levels in the hippocampus from the cognitive decline resulting from diabetes [18].

At the same time, the p-NF-kB p65/NF-kB p65 ratio was reversed from the increasing tendency in the SARS-CoV-2 $S$ and Danshensu groups. These results suggested that Danshensu, a p-NF-kB p65 inhibitor, performed a protective role against
SARS-CoV-2 S-induced acute lung inflammation in mice by suppressing inflammatory mediators release through the TLR4 and NF-KB p65 pathway. The anti-inflammation in this model, involving the attenuation of the TLR4 inflammatory signaling pathway and the reduction of p-NF-KB p65 levels, was a complicated mechanism. The release of inflammatory factors was promoted by the SARS-CoV-2 S-activated NF-KB p65, the critical transcription factor in inflammation, and was inhibited by pretreatment with Danshensu. We also measured antioxidant factors and found that CAT levels were reversed by Danshensu, and GPx levels could be reversed in some cases. It indicated that SARS-CoV-2 S-induced significantly elevated phosphorylation of NF-kB p65 was attenuated by Danshensu pretreatment. We also found that inflammatory responses regulated by TLR4 and NF-KB p65, which was consistent with previous reports [47]. Taken together, our results suggested that the production of TLR4/NF-KB p65 signaling components-activated inflammatory cytokines were decreased with the anti-inflammatory activity of Danshensu.

Previous evidence showed that nosogenesis of lung inflammation was caused by the entrance of binding of the SARS-CoV-2 Spike protein's S1 subunit to ACE2 on the target cell surface [4850]. Under the circumstance of decline of ACE2 expression, phosphorylation of NF-KB p65 releases inflammatory signaling. In this study, different concentrations of Danshensu were conducted to SARS-CoV-2 S-induced mice and we found it could significantly promote the mRNA expression of ACE2 and reverse the mRNA expression of angiotensinogen (AGT). More recently, plenty of research indicated that ACE2 is the cellular receptor of SARS-CoV-2 [51-53], involvement of ACE2 in ALI has been confirmed in various animal models aroused by SARS-CoV and SARS-CoV-2 [54, 55], the established model of mice with humanized ACE2 has also been 
used for the anti-coronavirus in vivo experiments in BSL-3 equipment [56]. A careful intervention of ACE2/Ang 1-7 axis could mitigate SARS-induced tissue injuries, which represents the protection can be offered with ACE2 in ALI even it provides a facilitation for virus entering at the epithelial surface [54, 57]. Our results showed that ACE2 and AGT levels could be reversed by the pretreatment with Danshensu after SARS-CoV-2 S stimulation. In previous studies, administration of ACE2 was demonstrated to ameliorate the damage in lung and vascular tissue and attenuate the systemic inflammation, the disorder on the expression of ACE2 has also been involved in acute lung inflammation through an imbalance in the RAS [58-61]. AGT is an acute-phase protein in the inflammatory process of COVID-19 patients, and the deficiency of ACE2 might result in marked upregulation of Ang II transformed from AGT, while Ang II could directly stimulates pro-inflammatory mediators resulting in the infiltration of macrophages [62-64]. In this study, results indicated that Danshensu mediated increase in ACE2 and decrease in AGT expression, resulting in the upregulation of antioxidant enzyme expression. There changes were related with anti-inflammatory and antioxidant properties of Danshensu.

Therefore, we confirmed that Danshensu could induce the expression of antioxidant enzyme and suppress the production of inflammatory mediator as a beneficial anti-inflammatory agent in vivo. ALI in mice could be induced by SARS-CoV-2 S and reversed in biochemical and pathological indexes by Danshensu. Meanwhile, our results revealed that the model induced by SARS-CoV-2 S via trachea could be used for the experiment in vivo of antiinflammatory drug for the inflammatory response of COVID-19.

\section{ACKNOWLEDGEMENTS}

These authors gratefully acknowledge financial support from the Major Scientific and Technological Projects of Guangdong Province (2019B020202002) and Chinese Academy of Traditional Chinese Medicine (ZZ13-035-02, 2019XZZX-LG04) to SWL; Guangzhou Science and Technology Program (202008040001, 201803040006 to WX and 2020B111110001 to SWL); National Natural Science Foundation of China (82070083 to GDH).

\section{AUTHOR CONTRIBUTIONS}

SWL contributed to the conception and design; WW, SSL, XFX, CY, XGN, SXY, XYP, WX and GDH contributed to the acquisition of data or analysis and interpretation of data; WW, SSL and XFX drafted the paper; SWL and CW supervised the experiments. All authors read and approved the final version to be published.

\section{ADDITIONAL INFORMATION}

Competing interests: The authors declare no competing interests.

\section{REFERENCES}

1. Zheng L, Zhang L, Huang J, Nandakumar KS, Liu S, Cheng K. Potential treatment methods targeting 2019-nCoV infection. Eur J Med Chem. 2020;205:112687.

2. McIntosh K, Dees JH, Becker WB, Kapikian AZ, Chanock RM. Recovery in tracheal organ cultures of novel viruses from patients with respiratory disease. Proc Natl Acad Sci USA. 1967;57:933-40.

3. Perlman S, Netland J. Coronaviruses post-SARS: update on replication and pathogenesis. Nat Rev Microbiol. 2009;7:439-50.

4. Chen N, Zhou M, Dong X, Qu J, Gong F, Han Y, et al. Epidemiological and clinical characteristics of 99 cases of 2019 novel coronavirus pneumonia in Wuhan, China: a descriptive study. Lancet. 2020;395:507-13.

5. Li YP, Ma Y, Wang N, Jin ZB. Eyes on coronavirus. Stem Cell Res. 2021;51:102200.

6. Wang D, Hu B, Hu C, Zhu F, Liu X, Zhang J, et al. Clinical characteristics of 138 hospitalized patients with 2019 novel coronavirus-infected pneumonia in Wuhan China. JAMA. 2020;323:1061-9.

7. Huang C, Wang Y, Li X, Ren L, Zhao J, Hu Y, et al. Clinical features of patients infected with 2019 novel coronavirus in Wuhan, China. Lancet. 2020;395:497-506.

8. Acter T, Uddin N, Das J, Akhter A, Choudhury TR, Kim S. Evolution of severe acute respiratory syndrome coronavirus 2 (SARS-CoV-2) as coronavirus disease 2019
(COVID-19) pandemic: a global health emergency. Sci Total Environ. 2020;730:138996.

9. Peiris J, Chu C, Cheng V, Chan K, Hung I, Poon L, et al. Clinical progression and viral load in a community outbreak of coronavirus-associated SARS pneumonia: a prospective study. Lancet. 2003;361:1767-72.

10. Harrison AG, Lin T, Wang P. Mechanisms of SARS-CoV-2 transmission and pathogenesis. Trends Immunol. 2020;41:1100-15.

11. Xu Z, Shi L, Wang Y, Zhang J, Huang L, Zhang C, et al. Pathological findings of COVID-19 associated with acute respiratory distress syndrome. Lancet Respir Med. 2020;8:420-2.

12. Fan E, Brodie D, Slutsky AS. Acute respiratory distress syndrome: advances in diagnosis and treatment. JAMA. 2018;319:698-710.

13. Standiford TJ, Ward PA. Therapeutic targeting of acute lung injury and acute respiratory distress syndrome. Transl Res J Lab Clin Med. 2016;167:183-91.

14. Chan JF, Kok KH. Genomic characterization of the 2019 novel human-pathogenic coronavirus isolated from a patient with atypical pneumonia after visiting Wuhan. Emerg Microbes Infect. 2020; 9:221-36.

15. Chen Y, Liu Q, Guo D. Emerging coronaviruses: genome structure, replication, and pathogenesis. J Med Virol. 2020;92:418-23.

16. Wu A, Peng $Y$, Huang $B$, Ding $X$, Wang $X$, Niu $P$, et al. Genome composition and divergence of the novel coronavirus (2019-nCoV) originating in China. Cell host microbe. 2020;27:325-8.

17. Jin $\mathrm{YH}$, Cai L, Cheng ZS, Cheng H, Deng T, Fan YP, et al. A rapid advice guideline for the diagnosis and treatment of 2019 novel coronavirus (2019-nCoV) infected pneumonia (standard version). Mil Med Res. 2020;7:4.

18. Zhang J, Zhang Q, Liu G, Zhang N. Therapeutic potentials and mechanisms of the Chinese traditional medicine Danshensu. Eur J Pharmacol. 2019;864:172710.

19. Bao XY, Zheng Q, Tong Q, Zhu PC, Zhuang Z, Zheng GQ, et al. Danshensu for myocardial ischemic injury: preclinical evidence and novel methodology of quality assessment tool. Front Pharmacol. 2018;9:1445.

20. Xu H, Liu W, Liu T, Su N, Guo C, Feng X, et al. Synergistic neuroprotective effects of Danshensu and hydroxysafflor yellow $A$ on cerebral ischemia-reperfusion injury in rats. Oncotarget. 2017;8:115434-43.

21. Jiang L, Wang J, Ju J, Dai J. Salvianolic acid B and sodium tanshinone II A sulfonate prevent pulmonary fibrosis through anti-inflammatory and anti-fibrotic process. Eur J Pharmacol. 2020;883:173352.

22. Luo J, Zhang L, Zhang $X$, Long $Y$, Zou F, Yan $C$, et al. Protective effects and active ingredients of Salvia miltiorrhiza Bunge extracts on airway responsiveness, inflammation and remodeling in mice with ovalbumin-induced allergic asthma. Phytomedicine. 2019;52:168-77.

23. Yang C, Pan X, Xu X, Cheng C, Huang Y, Li L, et al. Salvianolic acid C potently inhibits SARS-CoV-2 infection by blocking the formation of six-helix bundle core of spike protein. Signal Transduct Target Ther. 2020; 5: 220.

24. Ye R, Liu Z. ACE2 exhibits protective effects against LPS-induced acute lung injury in mice by inhibiting the LPS-TLR4 pathway. Exp Mol Pathol. 2020;113:104350.

25. Chan CK, Tan LT, Andy SN, Kamarudin MNA, Goh BH, Kadir HA. Antineuroinflammatory activity of Elephantopus scaber L. via activation of Nrf2/HO1 signaling and inhibition of p38 MAPK pathway in LPS-induced microglia BV-2 cells. Front Pharmacol. 2017;8:397.

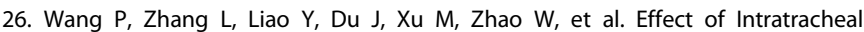
instillation of $\mathrm{ZnO}$ nanoparticles on acute lung inflammation induced by lipopolysaccharides in mice. Toxicol Sci. 2020;173:373-86.

27. Wang W, Wu L, Li Q, Zhang Z, Xu L, Lin C, et al. Madecassoside prevents acute liver failure in LPS/D-GalN-induced mice by inhibiting p38/NF-KB and activating Nrf2/HO-1 signaling. Biomed Pharmacother. 2018;103:1137-45.

28. Li L, Liu Y, Zhao X, Qi C, Zhang Y, Zhang Y, et al. Salvianic acid A sodium promotes the recovery of motor function after spinal cord injury in rats by reducing microglia inflammation through regulating MIP2/Vdac1/Ndufa12 signaling axis. Orthop Surg. 2020;12:1971-9.

29. Li Y, Chen H, Yang Y, Niu M, Wang J, Wu Y, et al. Danshen formula granule and salvianic acid A alleviate ethanol-induced neurotoxicity. J Nat Med. 2020;74:399-408.

30. Jia D, Zhang CZ, Qiu Y, Chen XF, Jia L, Chen AF, et al. Cardioprotective mechanisms of salvianic acid $A$ sodium in rats with myocardial infarction based on proteome and transcriptome analysis. Acta Pharmacol Sin. 2019;40:1513-22.

31. Bourgonje A. R., Abdulle A. E., Timens W. Angiotensin-converting enzyme 2 (ACE2), SARS-CoV-2 and the pathophysiology of coronavirus disease 2019 (COVID-19). J Pathol. 2020; 251: 228-48.

32. Nie J, Li Q, Wu J, Zhao C, Hao H, Liu H, et al. Establishment and validation of a pseudovirus neutralization assay for SARS-CoV-2. Emerg Microbes Infect. 2020;9:680-6

33. Szarka RJ, Wang N, Gordon L, Nation PN, Smith RH. A murine model of pulmonary damage induced by lipopolysaccharide via intranasal instillation. J Immunol Methods. 1997;202:49-57. 
34. Li H, Liu L, Zhang D, Xu J, Dai H, Tang N, et al. SARS-CoV-2 and viral sepsis: observations and hypotheses. Lancet. 2020;395:1517-20.

35. Freshney NW, Rawlinson L, Guesdon F, Jones E, Cowley S, Hsuan J, et al. Interleukin-1 activates a novel protein kinase cascade that results in the phosphorylation of Hsp27. Cell. 1994;78:1039-49.

36. Lee JC, Laydon JT, McDonnell PC, Gallagher TF, Kumar S, Green D, et al. A protein kinase involved in the regulation of inflammatory cytokine biosynthesis. Nature. 1994;372:739-46.

37. Han J, Lee JD, Bibbs L, Ulevitch RJA. MAP kinase targeted by endotoxin and hyperosmolarity in mammalian cells. Science. 1994;265:808-11.

38. Seneviratne AN, Monaco C. Role of inflammatory cells and toll-like receptors in atherosclerosis. Curr Vasc Pharmacol. 2015;13:146-60.

39. Yang XL, Guo TK, Wang YH, Huang YH, Liu X, Wang XX, et al. Ginsenoside Rd attenuates the inflammatory response via modulating p38 and JNK signaling pathways in rats with TNBS-induced relapsing colitis. Int Immunopharmacol. 2012;12:408-14.

40. Wang S, Hibberd ML, Pettersson S, Lee YK. Enterococcus faecalis from healthy infants modulates inflammation through MAPK signaling pathways. PLoS One. 2014;9:e97523.

41. Li Q, Verma IM. NF-KB regulation in the immune system. Nat Rev Immunol. 2002;2:725-34

42. Enomoto $N$, Takei $\mathrm{Y}$, Hirose $\mathrm{M}$, Ikejima $\mathrm{K}$, Miwa $\mathrm{H}$, Kitamura $\mathrm{T}$, Sato $\mathrm{N}$. Thalidomide prevents alcoholic liver injury in rats through suppression of Kupffer cell sensitization and TNF-alpha production. Gastroenterology. 2002;123:291-300.

43. Barnes PJ, Karin M. Nuclear factor-kB: a pivotal transcription factor in chronic inflammatory diseases. N Engl J Med. 1997;336:1066-71.

44. Tak PP, Firestein GS. NF-KB: a key role in inflammatory diseases. J Clin Invest. 2001;107:7-11.

45. Mattson MP, Camandola S. NF-KB in neuronal plasticity and neurodegenerative disorders. J Clin Invest. 2001;107:247-54.

46. Lam FF, Yeung JH, Chan KM, Or PM. Relaxant effects of danshen aqueous extract and its constituent danshensu on rat coronary artery are mediated by inhibition of calcium channels. Vasc Pharmacol. 2007;46:271-7.

47. Matsuyama T, Kubli SP, Yoshinaga SK, Pfeffer K. An aberrant STAT pathway is central to COVID-19. Cell Death Differ. 2020; 27:3209-25.

48. Shang J, Ye G, Shi K, Wan Y, Luo C, Aihara H. Structural basis of receptor recognition by SARS-CoV-2. Nature. 2020; 581: 221-4.

49. Wang Q, Zhang Y, Wu L, Niu S, Song C, Zhang Z, Lu G, Qiao C, Hu Y, Yuen KY, Wang Q, Zhou H, Yan J, Qi J. Structural and functional basis of SARS-CoV-2 entry by using human ACE2. Cell. 2020;181:894-904.e9.
50. Wan Y., Shang J., Graham R., Baric R. S., Li F. Receptor recognition by the novel coronavirus from wuhan: an analysis based on decade-long structural studies of SARS coronavirus. J. Virol. 2020;94:e00127-20.

51. Wang K, Gheblawi M, Oudit GY. Angiotensin converting enzyme 2: a doubleedged sword. Circulation. 2020;142:426-8.

52. Walls AC, Park YJ, Tortorici MA, Wall A, McGuire AT, Veesler D. Structure, function, and antigenicity of the SARS-CoV-2 spike glycoprotein. Cell. 2020;181:281-92.e6.

53. Yan R., Zhang Y. Structural basis for the recognition of SARS-CoV-2 by full-length human ACE2. Science. 2020; 367:1444-8.

54. Imai Y, Kuba K, Rao S, Huan Y, Guo F, Guan B, et al. Angiotensin-converting enzyme 2 protects from severe acute lung failure. Nature. 2005:436:112-6.

55. Yilin Z, Yandong N, Faguang J. Role of angiotensin-converting enzyme (ACE) and ACE2 in a rat model of smoke inhalation induced acute respiratory distress syndrome. Burns. 2015;41:1468-77.

56. Hansen J, Baum A. Studies in humanized mice and convalescent humans yield a SARS-CoV-2 antibody cocktail. Science. 2020;369:1010-4.

57. Kuba K, Imai Y, Rao S, Gao H, Guo F, Guan B, et al. A crucial role of angiotensin converting enzyme 2 (ACE2) in SARS coronavirus-induced lung injury. Nat Med. 2005;11:875-9.

58. Gheblawi M, Wang K, Viveiros A, Nguyen Q, Zhong JC, Turner AJ, et al. Angiotensin-converting enzyme 2: SARS-CoV-2 receptor and regulator of the renin-angiotensin system: celebrating the 20th anniversary of the discovery of ACE2. Circ Res. 2020;126:1456-74.

59. Rey-Parra GJ, Vadivel A, Coltan L, Hall A, Eaton F, Schuster M, et al. Angiotensin converting enzyme 2 abrogates bleomycin-induced lung injury. J Mol Med. 2012;90:637-47.

60. Hemnes AR, Rathinasabapathy A, Austin EA, Brittain EL, Carrier EJ, Chen X, et al. A potential therapeutic role for angiotensin-converting enzyme 2 in human pulmonary arterial hypertension. Eur Respir J. 2018;51:1702638.

61. Khan A, Benthin C, Zeno B, Albertson TE, Boyd J, Christie JD, et al. A pilot clinical trial of recombinant human angiotensin-converting enzyme 2 in acute respiratory distress syndrome. Crit Care (Lond, Engl). 2017;21:234.

62. Wang J, Kaplan N, Wysocki J, Yang W, Lu K, Peng H, et al. The ACE2-deficient mouse: a model for a cytokine storm-driven inflammation. FASEB J. 2020;34:10505-15.

63. Tyagi SC, Singh M. Multi-organ damage by Covid-19: congestive (cardio-pulmonary) heart failure, and blood-heart barrier leakage. Mol Cell Biochem. 2021;476:1891-5.

64. Ferrario CM, Ahmad S, Nagata S, Simington SW, Varagic J, Kon N, et al. An evolving story of angiotensin-ll-forming pathways in rodents and humans. Clin Sci. 2014;126:461-9. 